\title{
GENE PANEL STUDY FOR FAMILIAL PITUITARY ADENOMA
}

\section{EP-689}

Tatiana Borodich, Ekaterina Pigarova, Elena Przhiyalkovskaya, Larisa Dzeranova, Ludmila Rozhinskaya, Evgeny Vasilyev, Anatoly Tulpakov, Ivan Dedov

Endocrinology Research Centre, Moscow, Russian Federation

\section{Introduction}

Several genetic syndromes are associated with familial pituitary adenomas. The penetrance of clinical manifestations of these syndromes is not ubiquitous and this might be the reason for the lack of detection of genetic mutations when only one or few genes are studied.

\section{Aim}

Clinical characterization and molecular genetic study of a panel with 10 genes involved in formation of pituitary adenomas in familial setting.

\section{Materials and methods}

Study included 6 families (13 patients) with familial pituitary adenomas with no other features of known genetic syndromes.

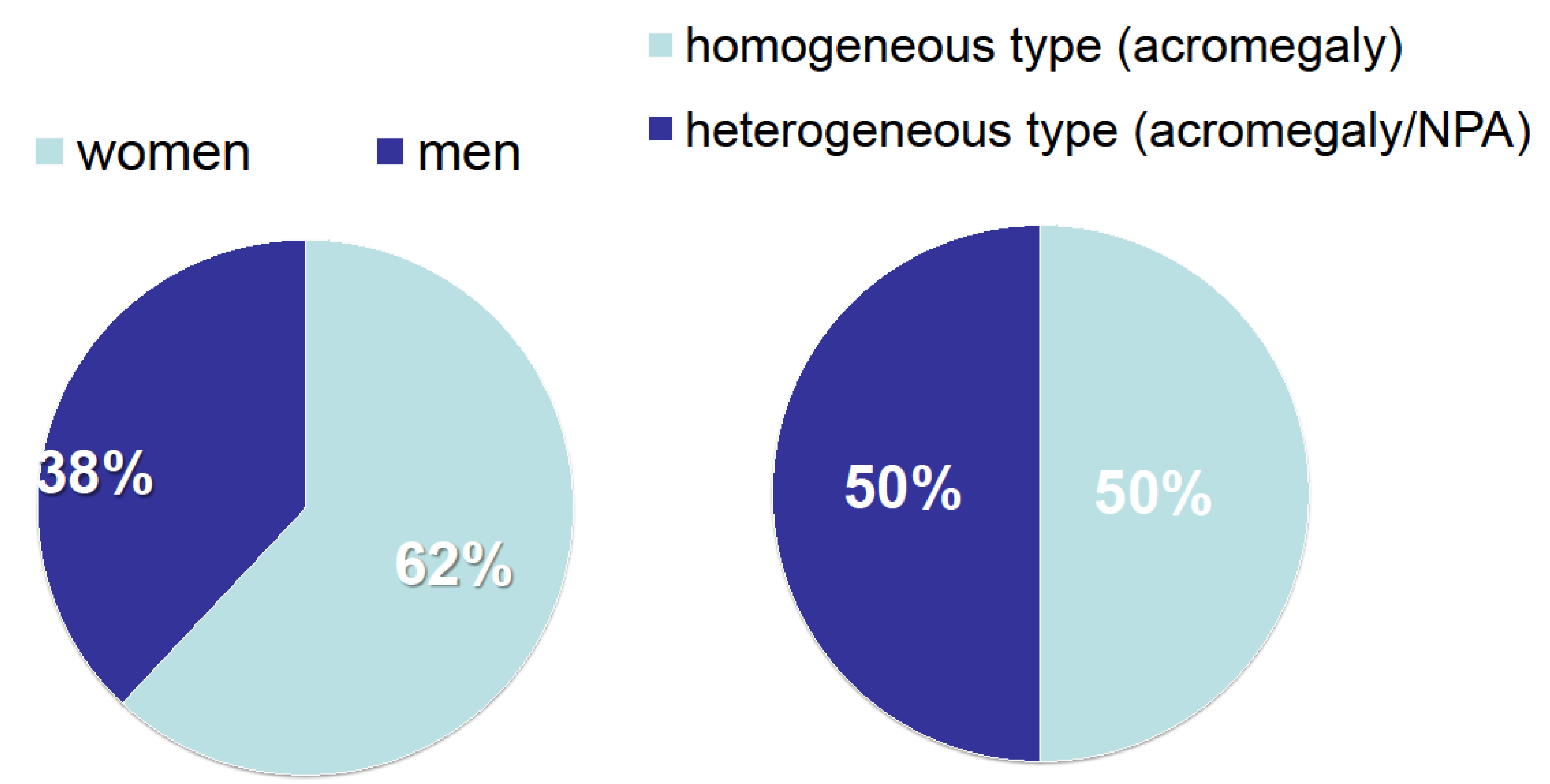

Genomic DNA from a blood samples of patients (probands) underwent high-throughput sequencing on the lon Torrent Personal Genome Machine (Life Technologies, USA) using a custom-designed AmpliSeq ${ }^{\mathrm{TM}}$ panel for the sequencing of a panel of genes (MEN1, CDKN1B, PRKAR1A, GNAS, AIP, SDHA, SDHB, SDHC, SDHD, PRKCA, CDKN2C, CDKN2A, POU1F1, PTTG2) but no pathological mutations were detected.

\begin{tabular}{|c|c|c|}
\hline \multicolumn{3}{|c|}{ Results } \\
\hline Parameter & Medium result & [Min - Max] \\
\hline $\begin{array}{c}\text { Growth } \\
\text { hormone }\end{array}$ & $13,9 \mathrm{ng} / \mathrm{ml}$ & {$[0,42-23,9]$} \\
\hline IGF-1 & $1517 \mathrm{ng} / \mathrm{ml}$ & [439 - 1871] \\
\hline Adenoma size & $7 \mathrm{~mm}$ & {$[5,5-17]$} \\
\hline
\end{tabular}

Tumor extensions

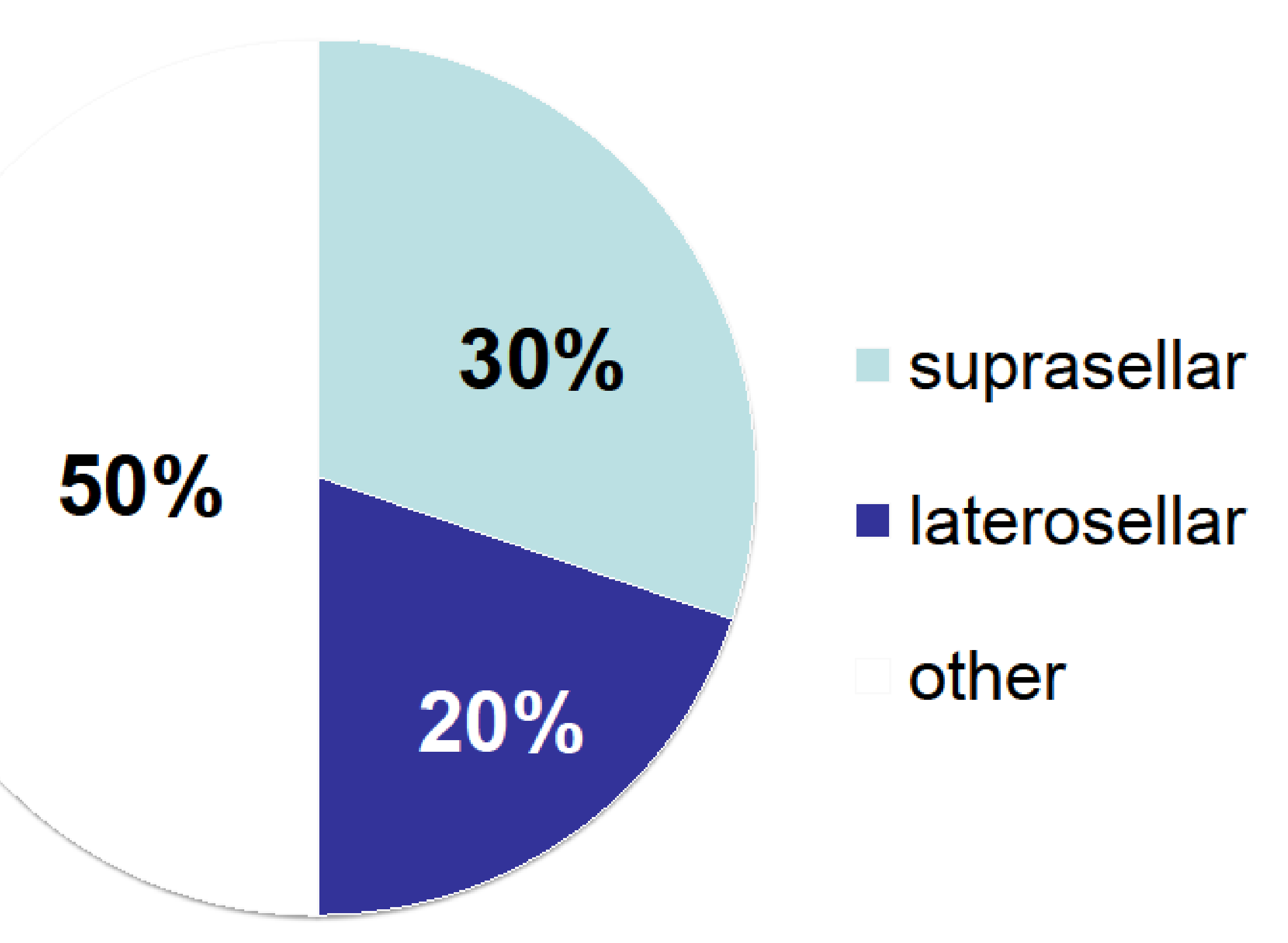

In most patients, adenomas were extended in more than 2 directions.

Median age was 55.6 years (40 to 69 years), the average height for females was $160 \mathrm{~cm}$, for males $170 \mathrm{~cm}$.

Most adenomas were $\mathrm{GH}$-producing and nonsecreting. The diagnosis of acromegaly was confirmed by hormone testing $(\mathrm{GH}>2.5 \mathrm{ng} / \mathrm{ml}$, no suppression on OGTT below $1 \mathrm{ng} / \mathrm{ml}$ and high IGF$1)$.

\section{Conclusions}

Families with hereditary pituitary adenomas can have tumors with homogenous and heterogeneous types of secretion. We were not able to show any genetic alteration in the group of patients studied. 